\title{
Flexural Behaviour of Geopolymer Concrete Beams using Recycled Waste Glass as Fine Aggregate
}

\author{
B. Parthiban, S. Thirugnanasambandam
}

\begin{abstract}
Cement substitutes and concrete alternatives are currently on the market to help in creating concrete a very ecofriendly material. In cement concrete production, heating and compounding method need large amounts of energy and emits minacious amounts of $\mathrm{CO} 2$ into the atmosphere. There has been an increasing significant interest in the development of cement less concrete called geopolymer concrete. In this study, cement is replaced entirely by ash and GGBS for making of geopolymer concrete. Now a days, the scarcity of river sand can have an effect on the development trade and hence there's a requirement of finding a replacement different material to switch the river sand. Non-reactive recycled waste glass is chosen as alternative to the river sand. Various grades of concrete including $M 20, M$ 40 and $M 60$ grades are developed in GP concrete and also same proportion is used for making GP concrete with glass aggregate. In geopolymer preparation, $\mathrm{NaOH}$ of 8 molarity concentration is used. Flexural behaviour of beams is studied by casting of nine beams of size $125 \mathrm{~mm} \times 200 \mathrm{~mm} \times 1100 \mathrm{~mm}$. The beams are designed as under reinforced sections. Out of nine beams, three beams of $M$ 20, $M 40$ and $M 60$ grade conventional cement concrete beams, three beams of GP beams and the remaining three beams are made with RWGFA in GP. Beams are tested under two point loading for flexure. The ultimate load carrying capability of all beams is obtained. The crack and deflections of the beams are studied. The experimental results are compared with finite element modeling using ANSYS software.

Index Terms - Cement Concrete (CC), Geopolymer concrete (GP), Ground Granulated Blast Furnace Slag (GGBS), Recycled Waste Glass Fine Aggregate (RWGFA), Flexural Behaviour, Deflected Shape of Beams.
\end{abstract}

\section{INTRODUCTION}

River sand and coarse aggregate are obtained from available source from nature. RWG isn't a decomposed material and nowadays it's drop on a land that becomes a extremely unsustainable possibility [1]. To seek out a more robust resolution to cut back the environmental problems caused by disposable of waste glass, it is used as fine mixture in concrete. In geopolymer concrete, ash and GGBS is $100 \%$ substitution for cement as binder with activator solution [2]. Use of this waste glass by dynamic it to mixture parts would possibly save lowland space and retain the existing natural resources. There has been an increasing significant interest in the increasing of production in concrete with RWGFA is effectively used [3]. This analysis work aims to review the practicableness of RWGFA as precursor to make alkali activated material (AAMs) beside

Revised Manuscript Received on April 12, 2019.

B. Parthiban, Research Scholar, Civil and Structural Engineering, Annamalai University, Annamalai Nagar, India. (balaparthi@gmail.com)

S. Thirugnanasambandam, Associate Professor, Civil and Structural Engineering, Annamalai University, Annamalai Nagar, India. (agstsai@gmail.com) ash. Fly ash and GGBS are chosen as the basic material to be activated by the geopolymerization process to be the concrete binder. The supply materialforgeopolymers supported alumina-silicate ought to be made in element $(\mathrm{Si})$ and aluminum (Al). In this research, caustic soda pellets $(\mathrm{NaOH})$ and glass $(\mathrm{Na} 2 \mathrm{SiO} 3)$ are used making alkaline activator. The size of the recycled waste glass is $3 \mathrm{~mm}$ and down $3 \mathrm{~mm}$ is used [4]. In earlier studies, researchers are focused glass as coarse aggregate in concrete and they establish larger size of waste glass material causes excessive expansion and affect the sturdiness of the concrete. Hence, RWGFA is used for making of GPC. It is also tested for flexural behaviour of GPC beams.

\section{EXPERIMENTAL PROGRAM}

\section{A. Fly Ash}

Low-calcium class F type fly ash is used for this study work and it is obtained from Tuticorin Thermal Power Station, Tamil Nadu, India. Category F type fly ash is used for this study work and it is obtained from Tuticorin Thermal Power Station, Tamil Nadu, India. Class F type fly ash is prosperous amount in silica and aluminina ( $\mathrm{Al}$ ) and less than $10 \%$ of lime $(\mathrm{CaO})$. Class $\mathrm{F}$ type fly ash is fine grained material of spherical and therefore the particle size distribution tests discovered that eighty percent of the ash are less than fifty microns. The specific gravity of Class $\mathrm{F}$ ash is 2.40The lighter in colour indicates lower carbon content presents in the ash.

\section{B. Ground Granulated Blast Furnace Slag (GGBS)}

GGBS are obtained from Toshaly cements private limited, Andhra Pradesh, India, conforming to IS: 12089 (1987). GGBS is the industrial by-product obtained from steel industry. In this geopolymer concrete production, the cement is substitute by ash and GGBS of equal quantity. GGBS is added necessarily for ambient curing conditions. The specific gravity of GGBS is 2.90 and the colour is white. The advantage of using GGBS using in geopolymer concrete production is to resist chemical attack and maintain excellent thermal properties.

\section{Sodium Hydroxide Pellets ( $\mathrm{NaOH})$}

Sodium hydroxide is accessible in solid state by means that of pellets. According to the purity the cost of the sodium hydroxide is varied. Attention is very much needed 
to prepare the hydroxide in water as a result of respectable heat is liberated by the reaction. Since our geopolymer concrete is undiversified material and its main method to activate the water glass. This research $94 \%$ to $96 \%$ purity which is the lowest cost is to be recommended for geopolymer concrete production.

\section{Sodium Silicate Solution $\left(\mathrm{Na}_{2} \mathrm{SiO}_{3}\right)$}

Water glass is a generic name for chemical compounds such as sodium meta silicate, sodium orthosilicate and sodium pyrosilicate. These are typically colourless clear solids or white powders, and soluble in water in varied amounts. Water glass $\left(\mathrm{Na}_{2} \mathrm{SiO}_{3}\right)$ is additionally referred to as liquid glass. Commonly it is used in the textile industry and soap manufacturing industry. In business, the assorted grade of water glass are characterized by their weight ratio. Water glass to hydroxide for this research is taken as 2.5 .

\section{E. Alkaline Solution}

Sodium hydroxide pellets $(\mathrm{NaOH})$ of 8 Molar $(8 \mathrm{M})$ is used for geopolymer concrete production. If the mass of $\mathrm{NaOH}$ is forty, so as to organize eight molar solutions, 320 grams of hydroxide pellets are dissolved in one litre water. Sodium hydroxide pellets $(\mathrm{NaOH})$ with $98 \%$ purity and sodium silicate solution $\left(\mathrm{Na}_{2} \mathrm{SiO}_{3}\right)$ is used for concrete production. The water glass with hydroxide hydroxide ratio by mass is taken as 2.5 . The alkaline solution is shown in Figure 4.5 and prepared prior to 24 hours of concrete manufacturing and it is used within 36 hours.

\section{F. Coarse Aggregate}

Coarse aggregate used are of machine crushed stone, angular in shape passing through twenty millimetre IS sieve and maintained on 4.75 millimetre IS sieve and it conforms to IS 383-1970. The precise gravity of coarse mixture is 2.76 and therefore the fineness modulus is 7.13 .

\section{G. Recycled Waste Glass as Fine Aggregate (RWGFA)}

In concrete production white clear white glass is used as fine aggregate. Before recycling process, the waste glass is washed to remove the impurities and the glass wastes are crushed and melted. After that it is screened into required size for immediate use. The size of the recycled waste glass is used $3 \mathrm{~mm}$ and down $3 \mathrm{~mm}$. The sample of RWGFA is shown in Figure one. The properties of RWGFA is given in Table 1. The Scanning Electron Micrograph (SEM) images of glass aggregates is shown in Figure 2. An X-Ray visible radiation $(\mathrm{XRF})$ is employed to work out the chemical constituent of the glass aggregate. The chemical element of glass aggregate fine mixture is given in Table 2.

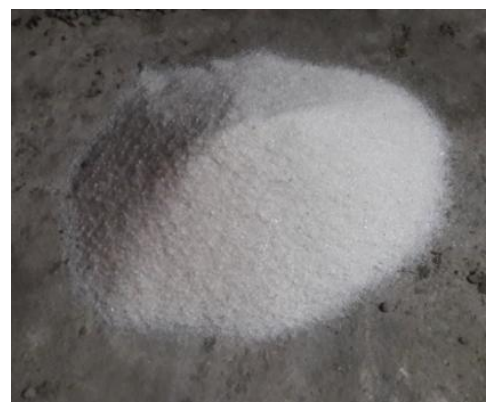

Figure 1 Recycled Glass Aggregate
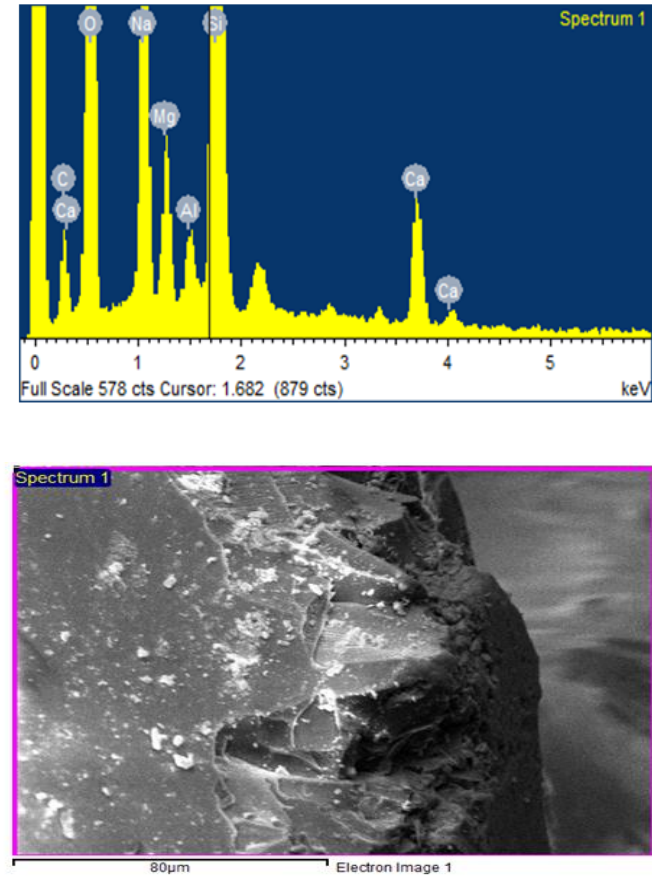

Figure 2 SEM Images of RWGFA

Table 1 Physical Properties of Recycled Waste Glass Fine Aggregate (RWGFA)

\begin{tabular}{|c|c|}
\hline Physical Property & Test Result \\
\hline Specific gravity & 2.56 \\
\hline Size of the aggregate & $3 \mathrm{~mm}$ and down $3 \mathrm{~mm}$ \\
\hline
\end{tabular}

Table 2 Chemical Constituents of RWGFA

\begin{tabular}{|c|c|}
\hline Constituent & In Percentage \\
\hline $\mathrm{SiO}_{2}$ & 78.01 \\
\hline $\mathrm{CaCO}_{3}$ & 7.83 \\
\hline $\mathrm{Na}$ & 8.60 \\
\hline $\mathrm{MgO}$ & 1.81 \\
\hline $\mathrm{Ca}$ & 3.02 \\
\hline $\mathrm{Al}_{2} \mathrm{O}_{3}$ & 0.61 \\
\hline
\end{tabular}

The RWGFA has possessed a virtually same quantity of silion oxide and better share (nearly 10\%) of aluminium oxide as natural sand. The calcium and sodium content in river sand are minimum (less than $3 \%$ ) as in RWGFA.

\section{H. Chemical Admixtures}

To maintain the slump and workability of the concrete, admixtures are used. Super plasticizer Conplast SP 430 is used in this concrete mix. The dosage of super plasticizer is $0.7 \%$ of the weight of the binder is used for his concrete production.

\section{Water}

Locally available potable water, without contamination is used for this work.

\section{J.Mixing, Casting and Curing}

Geopolymer concrete is made with same mix proportion used in M 20, M 40 and M 60 grade conventional cement 
concrete is designed for mix proportion by using IS Code 10262-2009 [5]. The mix proportion of M 20, M 40 and $\mathrm{M}$ 60 grade cement concrete is 1:2.75:3.36, 1:1.67:2.50 and 1:1.33:2.33 respectively. W/C ratio is used for $\mathrm{M} 20, \mathrm{M} 40$ and M 60 grade is used $0.50,0.39$ and 0.35 respectively. In geopolymer concrete preparation, $\mathrm{NaOH}$ of $8 \mathrm{M}$ is used in concrete mix. The geopolymer concrete constituents are ash, GGBS, RWGFA, gravel, water and super plasticizer. Water glass with $\mathrm{NaOH}$ pellets within the magnitude relation by mass 2.5 has been used for concrete manufacturing. Figure 3 shows the materials used for preparation of concrete. River sand is used for control mix geopolymer concrete and the same mix is used for $100 \%$ replaced with RWGFA. The constituent of geopolymer mix is given in Table 4.

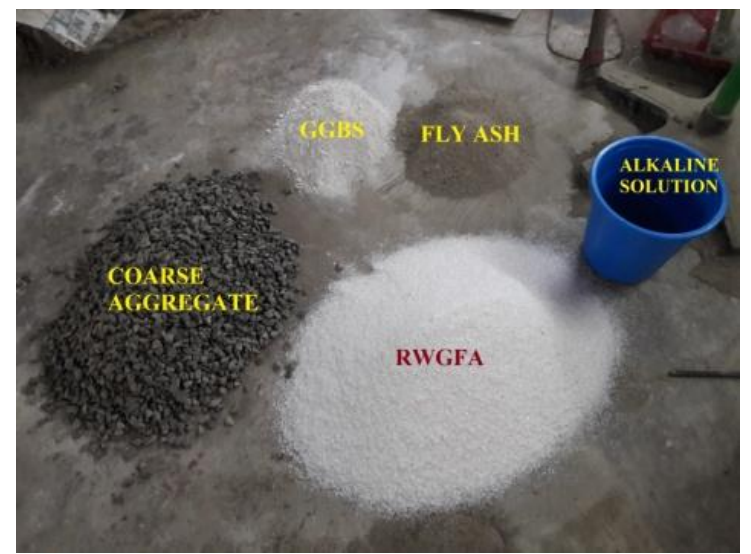

Figure 3 Materials used for RWGFA Geopolymer Concrete

For each mix M 20, M 40 and M 60 grade six cubes of size $100 \times 100 \times 100$ millimeter are cast to find the mechanical strength at 7 days, 28 days and for flexural behavior totally nine beams are cast. The size of beams are $125 \times 200 \times 1100$ millimeter long are cast in cement concrete, GPC and GPC with glass aggregate as fine aggregate. The samples are demoulded after one day and it is kept in room temperature for ambient condition.

Table 3 Constituents of Geopolymer Mix

\begin{tabular}{|c|c|c|c|}
\hline \multirow{2}{*}{ Constituents } & \multicolumn{3}{|c|}{ Quantity in m $^{\mathbf{3}}$} \\
\cline { 2 - 4 } & $\mathbf{M ~ 2 0}$ & $\mathbf{M ~ 4 0}$ & $\mathbf{M ~ 6 0}$ \\
\hline $\begin{array}{c}\text { Fly ash 50\% + } \\
\text { GGBS 50\% }\end{array}$ & 337.55 & 464.22 & 515.02 \\
\hline $\begin{array}{c}\left(\mathrm{Na}_{2} \mathrm{SiO}_{3}+\mathrm{NaOH}\right) / \\
\mathrm{Fly} \mathrm{Ash} \mathrm{\&} \mathrm{GGBS}\end{array}$ & 0.45 & 0.45 & 0.45 \\
\hline $\mathrm{Na}_{2} \mathrm{SiO}_{3} / \mathrm{NaOH}$ & 2.5 & 2.5 & 2.5 \\
\hline $\mathrm{NaOH} \mathrm{Pellets}$ & 13.89 & 19.10 & 21.19 \\
\hline $\mathrm{Na}_{2} \mathrm{SiO}$ & 108.50 & 149.21 & 165.54 \\
\hline $\mathrm{Water}_{3}$ & 29.51 & 40.51 & 45.01 \\
\hline $\begin{array}{c}\text { Fine Aggregate } \\
(\mathrm{Sand} / \mathrm{RWGFA})\end{array}$ & 928.26 & 775.24 & 684.98 \\
\hline Coarse Aggregate & 1134.17 & 1160.55 & 1200.00 \\
\hline SP & 2.24 & 4.39 & 5.88 \\
\hline
\end{tabular}

After seven and twenty eight days the cubes are tested. All above tests are carried out for conventional geopolymer concrete and glass aggregate concrete as per IS 516-1959.

\section{TESTING PROCEDURE}

\section{A. Compressive Strength}

For compression test, $1000 \mathrm{KN}$ capacity of compressive testing machine is used to apply the load. The load is gradually increases until the cube is failure. The maximum load taken by each specimen during the test is recorded. The mean value is the compressive strength of the sample. Results of M 20, M 40 and M 60 grade geopolymer control concrete and recycled waste glass fine aggregate (RWGFA) concrete are tabulated in Table four.

Table 4 Compressive Strength on GPC, RWGFA Concrete for M 20, M 40 and M 60 Grade Mix

\begin{tabular}{|c|c|c|c|}
\hline \multirow{4}{*}{ Grade } & \multirow{2}{*}{ Mix } & \multicolumn{2}{|c|}{$\begin{array}{c}\text { Compressive Strength } \\
\text { (MPa) }\end{array}$} \\
\cline { 3 - 4 } & & Seven Days & $\begin{array}{c}\text { Twenty } \\
\text { Eight Days }\end{array}$ \\
\hline \multirow{3}{*}{ M 20 } & CC & 18.83 & 28.00 \\
\cline { 2 - 4 } & GP & 19.00 & 29.00 \\
\cline { 2 - 4 } & GP (RWGFA) & 16.10 & 29.30 \\
\hline \multirow{3}{*}{ M 40 } & CC & 35.80 & 46.60 \\
\cline { 2 - 4 } & GP & 39.82 & 48.50 \\
\cline { 2 - 4 } & GP (RWGFA) & 39.70 & 48.56 \\
\hline \multirow{3}{*}{ M 60 } & CC & 51.42 & 68.50 \\
\cline { 2 - 4 } & GP & 56.80 & 70.10 \\
\cline { 2 - 4 } & GP (RWGFA) & 56.10 & 70.16 \\
\hline
\end{tabular}

\section{B. Flexural Behaviour of Geopolymer Concrete Beams andRWGFA Concrete Beams}

Beams are designed as under reinforced sections. Reinforcement bars of $8,10,12$ millimeter dia are used as longitudinal reinforcement and $8 \mathrm{~mm}$ diameter at $150 \mathrm{~mm}$ spacing is used as two legged vertical stirrups for shear reinforcement in all beams. For M 20 and M 40 grade mix 8 $\mathrm{mm}$ diameter bar is used in compression zone and $10 \mathrm{~mm}$ diameter bar is used in tension zone. For M 60 grade mix 10 $\mathrm{mm}$ diameter bar is used in compression zone and $12 \mathrm{~mm}$ diameter bar is used in tension zone. After 28 days in ambient curing, the geopolymer concrete, RWGFA concrete beam specimens are prepared for testing. The test set up is shown in Figure 4. The specimen in placed in $200 \mathrm{kN}$ capability frame. Geopolymer beam specimens are tested until its failure takes place when the load is increased monotonically. If the load is increased the beams are began to deflect and also the flexural cracks are enlarged in the center span of the beams. All beams are tested up to the ultimate load and the failure typically in flexure zone. The increase in mid-span deflection shows the function of increasing the load. The load deflection curves indicate distinct events that occurred throughout the check. The events are known as initial cracking, yield of the tensile 
reinforcement, crushing of concrete at the compressive face related to spalling concrete cover. The tensile steel must have reached its yield strength before failure due to the nature of the under reinforced section of the beams. The testing of beam under Flexural is shown in Figure 5. The flexural test results for M 20, M 40 and M 60 grade mix cement concrete, geopolymer concrete, and RWGFA geopolymer concrete are tabulated in Table 5.

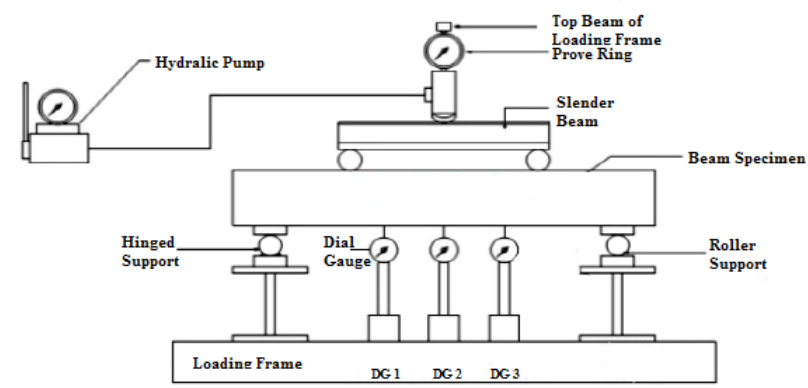

Figure 4 Test Set up of Beam

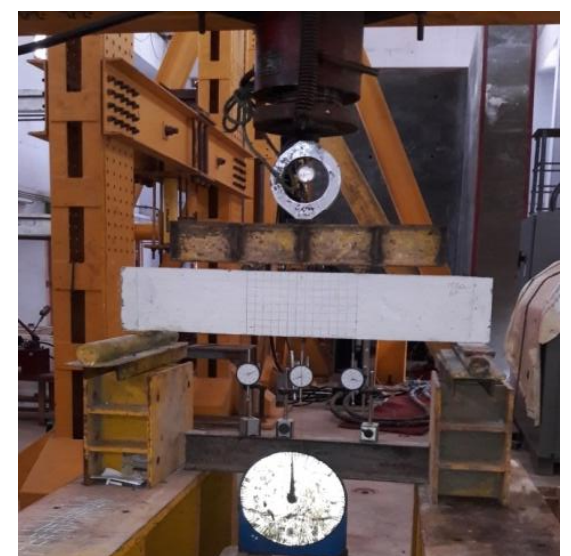

Figure 5 Testing of Beam Under Two Point Loading

Table 5 Test Result of Geopolymer Concrete and RWGFA Beams

\begin{tabular}{|c|c|c|c|c|c|c|}
\hline Grade & $\begin{array}{l}\text { Beam } \\
\text { Code }\end{array}$ & $\begin{array}{l}1^{\text {st }} \\
\text { Crack } \\
\text { Load } \\
(\mathbf{k N})\end{array}$ & $\begin{array}{l}\text { Service } \\
\text { Load } \\
(\mathbf{k N})\end{array}$ & $\begin{array}{l}\text { Yield } \\
\text { Load } \\
(\mathbf{k N})\end{array}$ & \begin{tabular}{|l} 
Ultimat \\
e \\
Load \\
$(\mathrm{kN})$
\end{tabular} & \begin{tabular}{|l} 
Max. \\
Deflecti \\
on \\
$(\mathbf{m m})$
\end{tabular} \\
\hline \multirow{3}{*}{ M 20} & $\mathrm{CC}$ & 40.00 & 54.33 & 80.50 & 82.50 & 16.00 \\
\hline & GP & 50.00 & 83.33 & 120.00 & 125.00 & 18.00 \\
\hline & $\begin{array}{c}\text { GP } \\
\text { (RWGFA) }\end{array}$ & 50.50 & 85.00 & 125.00 & 127.50 & 20.00 \\
\hline \multirow{3}{*}{ M 40} & $\mathrm{CC}$ & 37.50 & 56.68 & 80.00 & 85.00 & 22.00 \\
\hline & GP & 45.00 & 93.33 & 135.00 & 140.00 & 22.00 \\
\hline & $\begin{array}{c}\text { GP } \\
\text { (RWGFA) }\end{array}$ & 50.00 & 96.33 & 140.00 & 144.50 & 23.00 \\
\hline \multirow{3}{*}{ M 60} & $\mathrm{CC}$ & 45.00 & 63.33 & 92.50 & 95.00 & 24.00 \\
\hline & GP & 50.00 & 101.67 & 150.00 & 152.50 & 27.00 \\
\hline & $\begin{array}{c}\text { GP } \\
\text { (RWGFA) }\end{array}$ & 50.00 & 103.33 & 152.50 & 155.50 & 27.50 \\
\hline
\end{tabular}

The load deflection behaviour for M 20, M 40 and M 60 grade mix cement concrete beams, geopolymer concrete beams and RWGFA concrete beams are shown in Figure 6 to 8 .

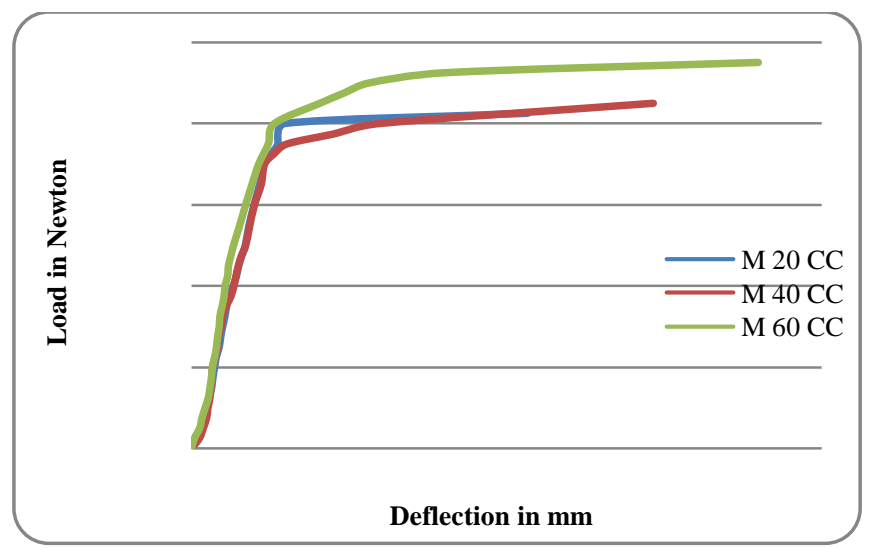

Figure 6 Load Deflection Curve of M 20 CC, M 40 CC and M 60 CC Beams

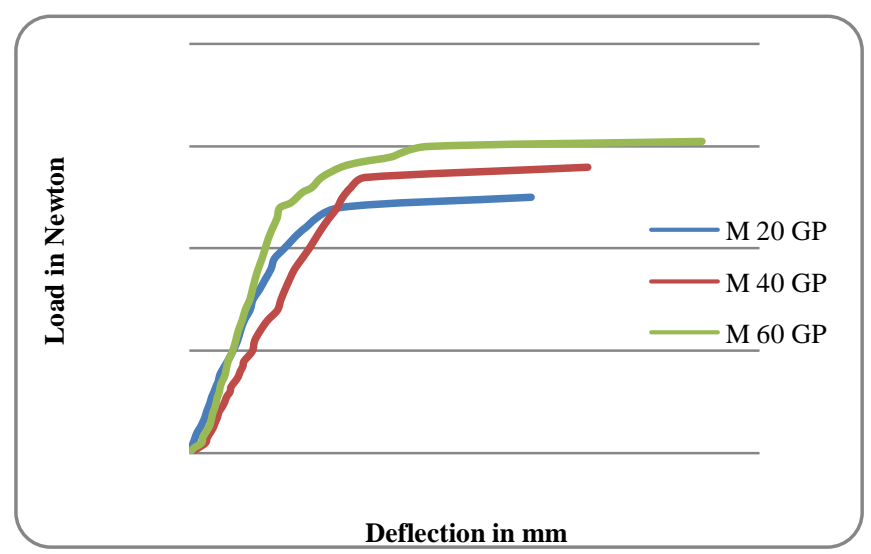

Figure 7 Load Deflection Curve of M 20 GP, M 40 GP and M 60 GP Beams

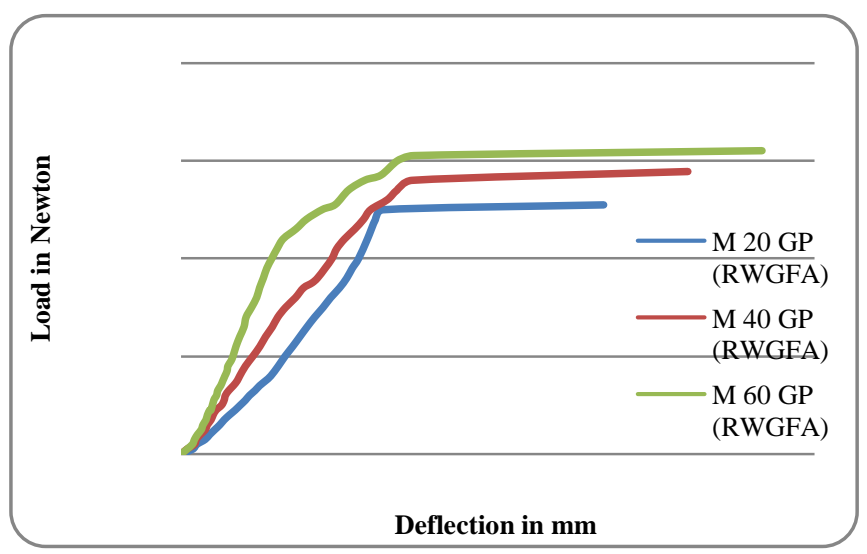

Figure 8 Load Deflection Curve of M 20 GP (RWGFA), M 40 GP (RWGFA) and M 60 GP (RWGFA) Beams

\section{Crack Patterns of Beam}

Failure pattern of beams are observed carefully. The flexure zone the cracks are developed when the load is applied. If the load is increased the existing cracks in flexure zones are widened and the new cracks are made on the span.

Because of the result of shear force, number of flexural cracks within the shear span

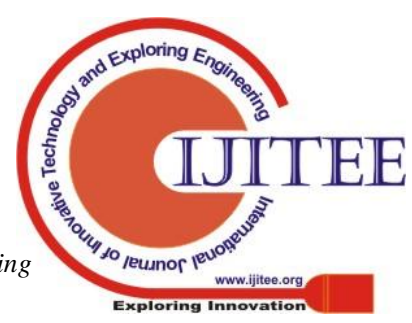


space was inclined cracks. All the cracks corresponded to flexural cracks with a variety varied between eleven and twenty six cracks and spacing locomotebetween 20 millimeter to 140 millimeter. The maximum load to yield load magnitude relation $\left(\mathrm{p}_{\mathrm{u}} / \mathrm{p}_{\mathrm{y}}\right)$ ranges between 1.02 and 1.06. The cracks at middle span opened wide close to failure. Throughout peak load, the beams deflected considerably, therefore indicating that the tensile steel should have yielded at failure. When the compression zone is crushed, the ultimate failure of the beam occurred in the midst of buckling of steel bars. The failure mode in all beams are that typical failure of an under-reinforced concrete beams. During the test, the crack patterns are measured with crack deflection microscope and the pattern of cracks are analyzed. During the test the crack width is marked every $25 \mathrm{kN}$. The width of crack is generally increased at tension zone and the cracks are perpendicular to the beam axis. In all the beams, mostly vertical cracks are appear in bending zone and inclined cracks are appeared in shear zone. The typical crack patterns of M 20, M 40 and M 60 grade mix geopolymer concrete and RWGFA concrete are shown in Figures 9 to 17.

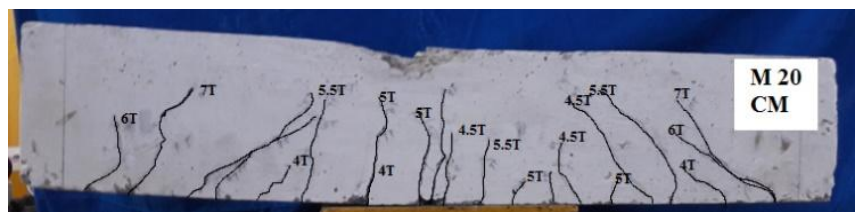

Figure 9 Crack Patterns of M 20 CC Beam

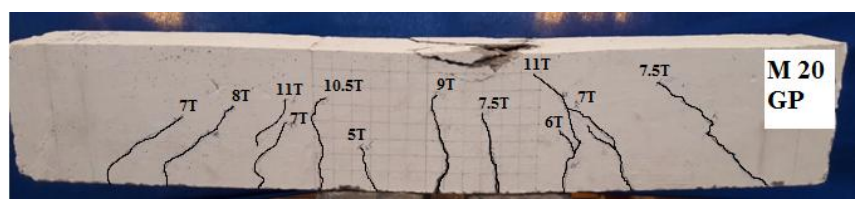

Figure 10 Crack Patterns of M 20 GP Beam

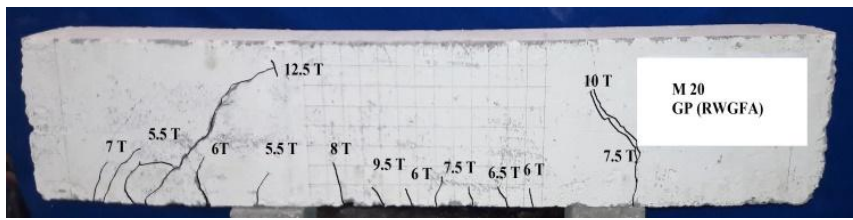

Figure 11 Crack Patterns of M 20 GP (RWGFA) Beam

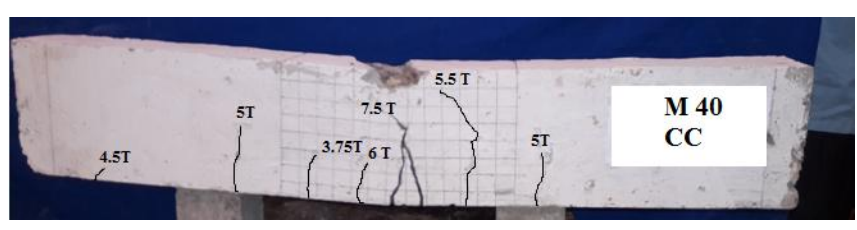

Figure 12 Crack Patterns of M 40 CC Beam

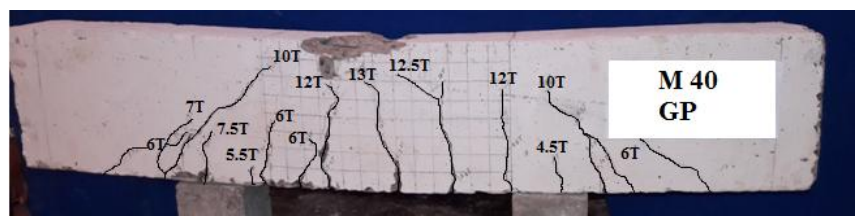

Figure 13 Crack Patterns of M 40 GP Beam

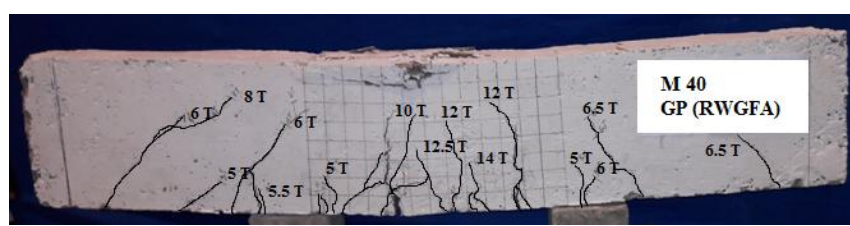

Figure 14 Crack Patterns of M 40 GP (RWGFA) Beam

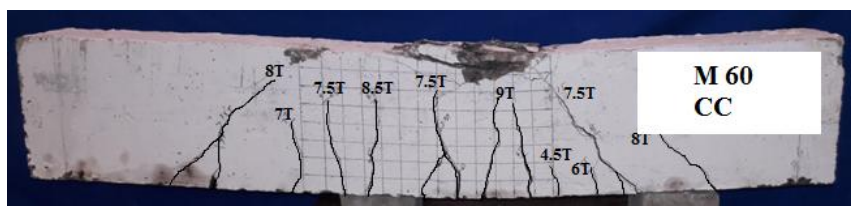

Figure 15 Crack Patterns of M 60 CC Beam

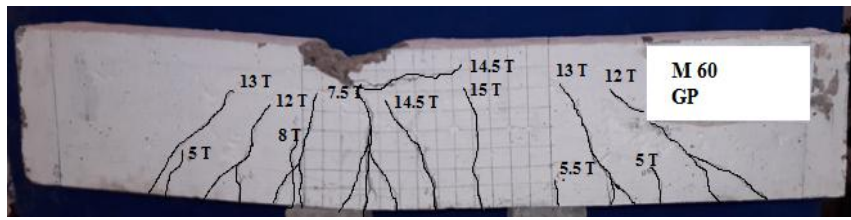

Figure 16 Crack Patterns of M 60 GP Beam

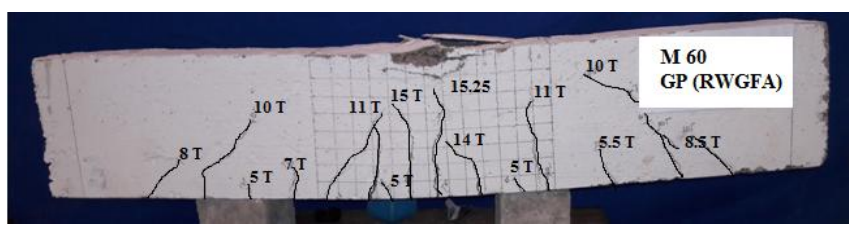

Figure 17 Crack Patterns of M 60 GP (RWGFA) Beam

D. Ductility Behaviour of Beams

The ductile flexural failure is characterized by the failure of rebar before the concrete and usually happens with large deformation when the rebar yields, it is a character of under reinforced sections. The displacement ductility characteristics of M 20, M 40 and M 60 grade cement concrete, geopolymer concrete and RWGFA geopolymer concrete beams are shown in Table 6.

Table 6 Ductility Displacement in Cement Concrete

Beams, Geopolymer Beams and RWGFA Beams

\begin{tabular}{|l|c|c|c|c|}
\hline \multirow{4}{*}{ Grade } & $\begin{array}{c}\text { Beam } \\
\text { Code }\end{array}$ & $\begin{array}{c}\text { Minimum } \\
\text { Deflection } \\
\Delta \mathbf{y}(\mathbf{m m})\end{array}$ & $\begin{array}{c}\text { Maximum } \\
\text { Deflection } \\
\Delta \mathbf{u}(\mathbf{m m})\end{array}$ & $\begin{array}{c}\text { Ductile } \\
\text { Ratio } \\
\boldsymbol{\mu}=\Delta \mathbf{u} / \Delta \mathbf{y}\end{array}$ \\
\hline \multirow{4}{*}{ M 20 } & CC & 4.46 & 16.00 & 3.59 \\
\cline { 2 - 5 } & GP & 7.96 & 18.00 & 2.26 \\
\cline { 2 - 5 } & $\begin{array}{c}\text { GP } \\
(\text { RWGFA) }\end{array}$ & 9.54 & 20.00 & 2.10 \\
\hline \multirow{3}{*}{ M 40 } & CC & 8.93 & 22.00 & 2.46 \\
\cline { 2 - 5 } & GP & 9.26 & 22.00 & 2.38 \\
\cline { 2 - 5 } & $\begin{array}{c}\text { GP } \\
(\text { RWGFA) }\end{array}$ & 10.94 & 23.00 & 2.01 \\
\hline \multirow{3}{*}{ M 60 } & CC & 11.50 & 24.00 & 2.09 \\
\cline { 2 - 5 } & GP & 12.55 & 27.00 & 2.15 \\
\cline { 2 - 5 } & GP & 11.02 & 27.50 & 2.50 \\
\hline & (RWGF) & & & \\
\hline
\end{tabular}

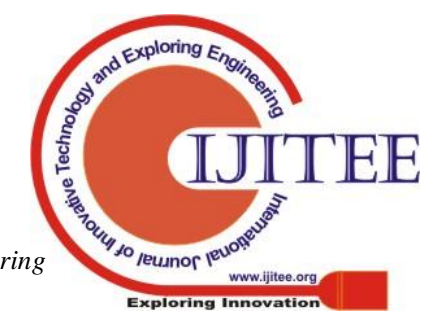




\section{ANSYS Modeling of Beams}

FEA software package ANSYS is adopted for predicting the load displacement response of geopolymer beam and RWGFA beams. For solid sixty five part the mesh was founded such sq. or rectangular parts and nodes within the concrete portion of the model. The mandatory part divisions are noted and modeling is mostly performed by mapped meshing (or) free meshing. The reinforcement model is meshed victimization line parts so the nodes of the road elements return precisely over the node of the solid elements that are unified so that each rebar parts and additionally the concrete parts share identical node. For beam generation total mesh model defined 4666 nodes and 3380 elements are required. These nodes and elements follows a procedure of concrete mapped mesh modeling in which meshes are generated in even order. Free mesh modeling is the one in which the meshes are generated in random. The meshing concrete is shown in Figure 18 and the meshing reinforcement is shown in Figure 19.

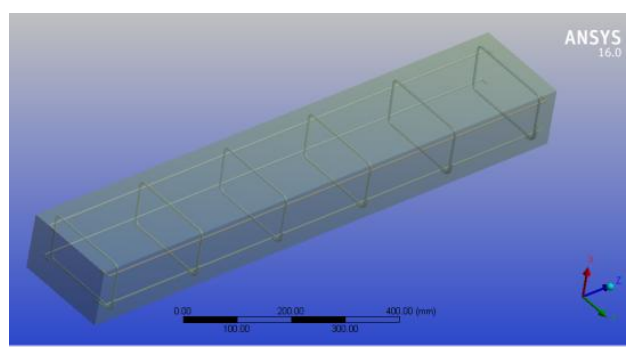

Figure 18 Meshing Concrete

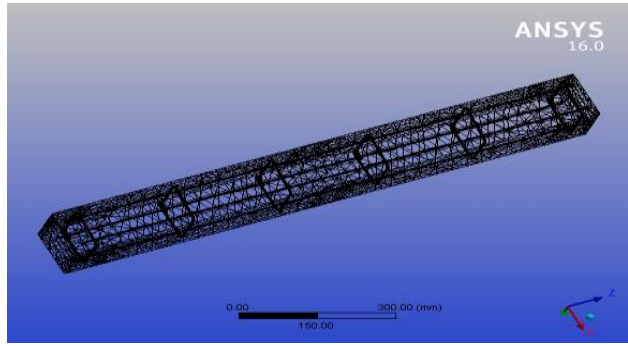

Figure 19 Meshing Reinforcement

The comparison of ultimate load and the experimental and numerical (ANSYS) results are tabulated in Table 7. A typical deflected shape of M 20, M 40 and M 60 grade mix cement concrete, geopolymer concrete and RWGFA geopolymer concrete are shown in Figures 20 to 22.

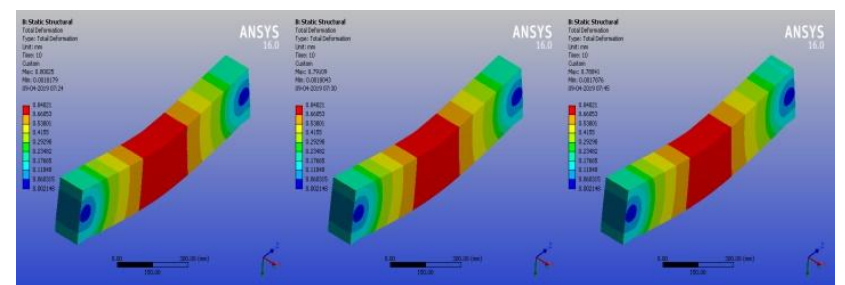

Figure 20 Deflection Shape of M 20 CC, M 20 GP and M 20 GP (RWGFA) Beams

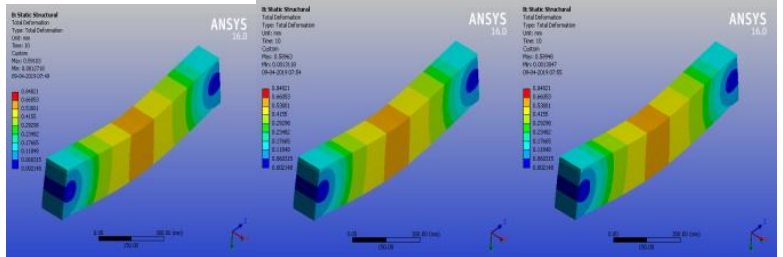

Figure 21 Deflection Shape of M 40 CC, M 40 GP and M 40 GP (RWGFA) Beams

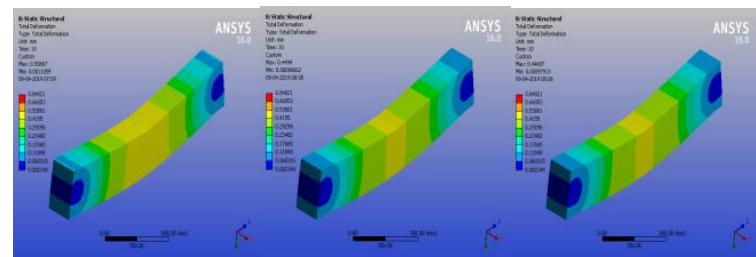

Figure 22 Deflection Shape of M 60 CC, M 60 GP and M 60 GP (RWGFA) Beams

\section{RESULTS AND DISCUSSIONS}

The characteristic of recycled glass fine mixture aren't considerably varied from the river sand. The non absorption of water in glass aggregate and free from roughness, the mechanical property is enhanced and the glass fine aggregate shows more cohesive then control mix concrete. The absorption of water can affect the strength parameters. The higher water absorption leads to lower strength. Recycled waste glass fine aggregate absorbs minimum quantity of water and the lower workability and hence the results of mechanical properties are better than the conventional concrete. The mean value of M 20, M 40 and M 60 grade mix cement concrete geopolymer mix and RWGFA mix are obtained. The compressive strength of RWGFA geopolymer mix is slightly higher than the cement concrete and geopolymer concrete.

Flexural behaviour of M 20, M 40 and M 60 cement concrete beams, geopolymer mix and RWGFA geopolymer mix are tabulated previously. The load deflection curve of cement concrete beams, geopolymer beams and RWGFA geopolymer beams are shown in figures. The crack patterns of the geopolymer beams made with river sand and RWGFA concrete beams made with recycled waste glass are shown and the failure patterns of RWGFA beams is similar to The characteristic of recycled glass fine mixture aren't considerably varied from the river sand. The non absorption of water in glass aggregate and free from roughness, the mechanical property is enhanced and the glass fine aggregate shows more cohesive then control mix concrete. The absorption of water can affect the strength parameters. The higher water absorption leads to lower strength. Recycled waste glass fine aggregate absorbs minimum quantity of water and the lower workability and hence the results of mechanical properties are better than the conventional concrete. The mean value of M 20, M 40 and M 60 grade mix cement concrete geopolymer mix and RWGFA mix are obtained. The compressive strength of RWGFA geopolymer mix is slightly higher than the cement concrete and geopolymer concrete. 
Flexural behaviour of M 20, M 40 and M 60 cement concrete beams, geopolymer mix and RWGFA geopolymer mix are tabulated previously. The load deflection curve of cement concrete beams, geopolymer beams and RWGFA geopolymer beams are shown in figures. The crack patterns of the geopolymer beams made with river sand and RWGFA concrete beams made with recycled waste glass are shown and the failure patterns of RWGFA beams is similar to geopolymer concrete. The comparison of ultimate load for all beam are shown in Figure 23

Table 7 Summary of Test Results for Geopolymer Concrete and RWGFA Beams

\begin{tabular}{|l|c|c|c|c|c|c|c|}
\hline \multirow{2}{*}{ Grade } & \multirow{2}{*}{$\begin{array}{c}\text { Beam } \\
\text { Code }\end{array}$} & \multicolumn{2}{|c|}{ Yield Load (kN) } & \multicolumn{2}{c|}{ Ultimate Load (kN) } & \multicolumn{2}{|c|}{ Maximum Deflection (mm) } \\
\cline { 3 - 8 } & Experimental & ANSYS & Experimental & ANSYS & Experimental & ANSYS \\
\hline \multirow{3}{*}{ M 20} & CC & 80.50 & 70.20 & 82.50 & 74.30 & 16.00 & 15.60 \\
\cline { 2 - 8 } & GP & 120.00 & 109.88 & 125.00 & 112.20 & 18.00 & 17.20 \\
\cline { 2 - 8 } & GP (RWGFA) & 125.00 & 112.60 & 127.50 & 117.50 & 20.00 & 17.50 \\
\hline \multirow{3}{*}{ M 40 } & CC & 80.00 & 72.00 & 85.00 & 74.80 & 22.00 & 20.10 \\
\cline { 2 - 8 } & GP & 135.00 & 123.90 & 140.00 & 126.90 & 22.00 & 20.60 \\
\cline { 2 - 8 } & GP (RWGFA) & 140.00 & 124.50 & 144.50 & 128.80 & 23.00 & 21.00 \\
\hline \multirow{3}{*}{ M 60 } & CC & 92.50 & 87.40 & 95.00 & 88.20 & 24.00 & 22.00 \\
\cline { 2 - 8 } & GP & 150.00 & 136.20 & 152.50 & 140.20 & 27.00 & 25.42 \\
\cline { 2 - 8 } & GP (RWGFA) & 152.50 & 138.70 & 155.00 & 141.80 & 27.50 & 24.50 \\
\hline
\end{tabular}

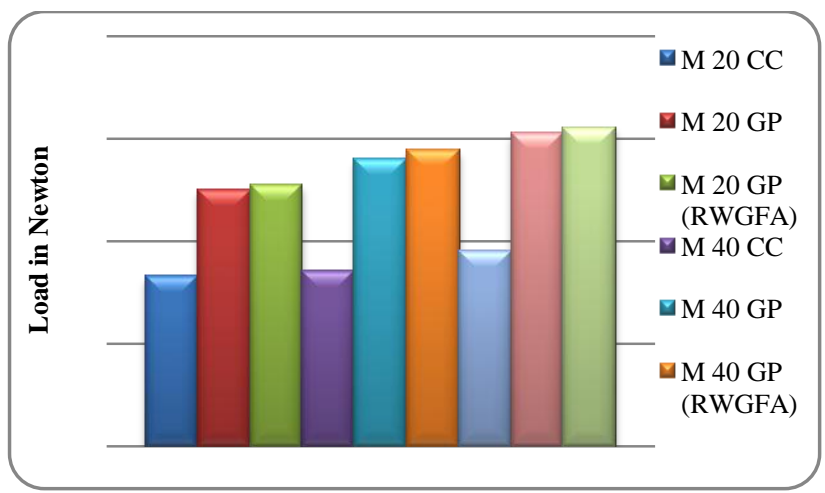

Figure 23Comparison of Ultimate load for M 20, M 40 and M 60 Beams

\section{CONCLUSION}

The following determinations are drawn from the test results. Recycled waste glass fine aggregate (RWGFA) is effectively used instead of conventional river sand in geopolymer concrete. M 20, M 40 and M 60 grade mix cement concrete beam and geopolymer beams offlexural behaviour are compared with glass fine aggregate geopolymer beams. The ultimate load carrying capacity of glass fine aggregate geopolymer beams of M 20, M 40 and M 60 beams are 2\%,3\% and $2 \%$ higher than the conventional geopolymer concrete respectively. The number of cracks and width of the cracks of RWGFA geopolymer beams are not much difference compared with conventional geopolymer beam. The deflected shape of geopolymer beams and RWGFA geopolymer beams are compared with ANSYS modeling. The deflected shape and the deflection behaviours are similar to that of the beams tested experimentally.

\section{REFERENCES}

1. Ismail, ZZ \& Al-Hashmi, EA., "Recycling of waste glass as partial replacement for fine combination in concrete", WasteManag., vol 29,2009,pp.655-659.

2. Guru Jawahar J and G. Mounika, Strength properties of ash and GGBS based totally Geopolymer concrete, Asian Journal of technology, Vol.18, No.4 (2017)621-631.
3. Gum Sung Ryu. "The mechanical properties of ash primarily based geopolymer concrete with basic activators", Construction and Building Materials, Elsevier, forty seven (2013) 409-418.

4. B. Parthban, S. Thirugnanasambandam, "Durbility study on Eco-Friendly Geopolymer Concrete exploitation Waste glassascombination, (IJRSET) Volume vi, issue XI, November 2018, Page No.147-154.

5. IS 10262-2009 suggested pointers for concrete combine style, New Delhi, Asian country: Bureau of Indian common place.

\section{BIOGRAPHY}

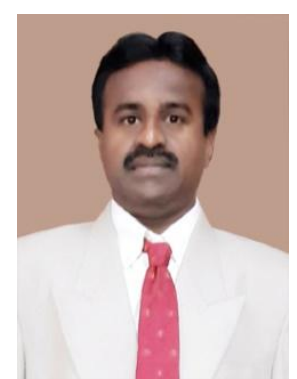

B. Parthiban received his Bachelor Degree and Master Degree in Department of Civil \&Strutural Engineering, Annamalai University. At present, he is pursuing Doctoral Degreee in Structural Engineering in Annamalai University. He had published Seven research papers in UGC Approved Journals. He had presented Two papers in National Conference and Two papers in International Conference.

E mail: balaparthi@gmail.com 


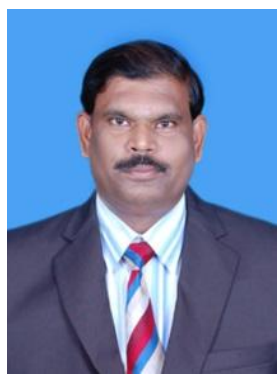

Dr.S.Thirugnanasambandam is presently working as Associate Professor in Annamalai University. He had completed his Master Degree and Doctoral Degree in Annamalai University. He is working in the Department of Civil and Structural Engineering since 1999. Four of his scholars awarded Ph.D., degree and presently guiding seven Ph.D., Scholars. He had published 74 research papers and attended many National and International Conference. His areas of interest are damage assessment and repair of structures. Also, he is familiar in development of Geopolymer Concrete Products.

E mail: agstsai@gmail.com 